\title{
Исследование механизмов поглощения ионов никеля почвой Удмуртии
}

\author{
(C) 2020 Шумилова М.А., Петров В.Г. \\ Удмуртский федеральный исследовательский центр УрО РАН, Ижевск
}

Поступила в редакцию 21.09.2020 г.

DOI: $10.17308 /$ sorpchrom.2020.20/3052

Доля загрязненных никелем почв в России (2.8\%) в ряду других тяжелых металлов (ТМ) является весьма значительной, что обусловлено разнообразием антропогенных источников его поступления. Для прогнозирования миграции элемента в почвенном покрове и разработки технологий по мелиорации земли в случае чрезвычайной ситуации необходимо изучение процесса его поглощения гумусовым горизонтом почв. Представленная работа посвящена исследованию специфической и неспецифической адсорбции никеля на примере типичных почв Удмуртской Республики.

В качестве объекта исследования выбраны верхние гумусированные горизонты трех типов почв Удмуртии: дерново-сильноподзолистой слабосмытой, дерново-карбонатной выщелоченной слабосмытой и серой лесной оподзоленной. Для минимизации влияния реакций ионного обмена на специфическую сорбцию предварительно проводилось насыщение почв кальцием из водного $0.01 \mathrm{M}$ раствора $\mathrm{CaCl}_{2}$, после чего пробы высушивались. Почвенную суспензию получали смешением воздушно-сухих образцов почвы с раствором с варьируемой концентрацией никеля в соотношении 1:10, перемешивали на ротаторе и отстаивали двое суток. Равновесную концентрацию ионов никеля в почвенном фильтрате определяли методом атомно-абсорбционной спектрометрии с электротермической атомизацией.

Изотермы ионообменной и специфической сорбции никеля по классификации Гилься относятся к ленгмюровскому типу и указывают на высокое сродство ионов металла к активным центрам почвенного поглощающего комплекса (ППК) всех исследуемых почв. С увеличением концентрации металла от 1.4 до 7.0 мМ зафиксировано максимальное снижение степени неспецифической сорбции практически вдвое для дерново-подзолистой почвы, в то время как для специфической адсорбции показатель снижался в 1.2 раза. Среди исследованных образцов почв только у дерново-подзолистой почвы зафиксировано преобладание специфического механизма сорбции никеля над ионообменным во всем интервале концентраций вводимого металла, что обусловливает его более прочную фиксацию ППК. При высокой концентрации вводимого металла (1.4-7.0 мМ) для дерново-карбонатной и серой лесной почв зафиксировано небольшое преобладание ионообменной адсорбции по сравнению со специфической.

Установлено, что практически для всех почв с увеличением концентрации никеля происходит снижение $\mathrm{pH}$ почвенного раствора. Только в случае ионообменной сорбции дерново-подзолистой почвы зафиксирована неизменная $\mathrm{pH}$, что указывает на отсутствие обменных реакций ионов никеля с протонами ППК. ции, почва.

Ключевые слова: никель, специфическая и неспецифическая адсорбция, изотерма адсорб-

\section{Введение}

В России доля загрязненных никелем почв (2.8\%) [1] является весьма значительной. Основными антропогенными источниками поступления никеля в окружающую среду являются предприятия металлургии, машиностроения и металлообработки, транспорт, сжигание каменного угля и мазута на ТЭЦ и в котельных, сточные воды [2]. Накапливаясь в почве, никель способствует созданию неблагоприятной 
экологической обстановки, поэтому необходим комплекс исследований для прогнозирования миграции элемента в почвенном покрове и разработка технологий по мелиорации земли в случае чрезвычайной ситуации. Работа посвящена изучению механизмов адсорбции никеля верхним гумусовым горизонтом типичных почв Удмуртской Республики.

\section{Экспериментальная часть}

В Удмуртии широко представлены дерново-подзолистые, дерновокарбонатные и серые лесные почвы [3], которые выбраны для изучения адсорбции никеля. Пробоподготовку почвенных образцов и определение рН солевой вытяжки, содержание гумуса и тяжелых металлов проводили в соответствии с требованиями стандартных методов [4], все почвы обладают тяжело-суглинистым гранулометрическим составом (табл. 1). Исходный раствор никеля $(\sim 0.1 \mathrm{M})$ готовился растворением навески $\mathrm{NiSO}_{4} \cdot 7 \mathrm{H}_{2} \mathrm{O}$, точная концентрация раствора определялась спектрометрически.

Таблица 1. Основные агрохимические показатели почвенных образцов

Table 1. Main agrochemical indicators of soil samples

\begin{tabular}{|c|c|c|c|c|c|c|c|}
\hline \multirow{2}{*}{$\begin{array}{l}\text { № } \\
\Pi / \Pi\end{array}$} & \multirow{2}{*}{ Тип почвы } & \multicolumn{3}{|c|}{ Содержание металла, мг·кг-1 } & \multirow{2}{*}{ Гумус, \% } & \multicolumn{2}{|c|}{$\mathrm{pH}$} \\
\hline & & $\mathrm{Mn}$ & $\mathrm{Fe}$ & $\mathrm{Al}$ & & $\mathrm{H}_{2} \mathrm{O}$ & $\mathrm{KCl}$ \\
\hline 1 & $\begin{array}{c}\text { Дерново- } \\
\text { сильноподзолистая } \\
\text { слабосмытая }\end{array}$ & 2.89 & 149.27 & 4620.40 & 1.58 & 6.23 & 5.22 \\
\hline 2 & $\begin{array}{c}\text { Дерново- } \\
\text { карбонатная выще- } \\
\text { лоченная слабосмы- } \\
\text { тая }\end{array}$ & 2.10 & 150.56 & 6753.20 & 3.28 & 6.63 & 5.57 \\
\hline 3 & $\begin{array}{c}\text { Серая лесная опод- } \\
\text { золенная }\end{array}$ & 2.22 & 131.98 & 4175.80 & 4.74 & 6.41 & 5.37 \\
\hline
\end{tabular}

Для обеспечения сопоставимых условий взаимодействия ионов никеля с ППК исследования проводили на фоне $0.01 \mathrm{M}$ раствора $\mathrm{CaCl}_{2}$ при соотношении почва : раствор=1:10. Для снижения до минимума влияния реакций ионного обмена на специфическую сорбцию, предварительно проводили насыщение почв кальцием из водного $0.01 \mathrm{M}$ раствора $\mathrm{CaCl}_{2}$, после чего пробы высушивали. Воздушно-сухие почвенные образцы массой 18 г, измельченные до размера частиц $<0.1$ мм, помещали в центрифужные колбы, к ним добавляли по $180 \mathrm{~cm}^{3}$ раствора с варьируемой концентрацией никеля в интервале от 0.0001 до 0.0028 М. Затем колбы с суспензиями взбалтывали два часа на ротаторе и отстаивали двое суток для установления химического равновесия, после чего пробы центрифугировали. В надосадочной жидкости определяли равновесную концентрацию ионов методом атомно-абсорбционной спектрометрии с электротермической атомизацией на приборе «Shimadzu-AA7000».

Количество поглощенных ионов металла рассчитывали по разности между исходными и равновесными концентрациями в жидкой фазе. Все экспериментальные точки получены в трех повторностях, опыт проводился в двух параллелях. Приведенные данные являются их средними величинами; значение относительного стандартного отклонения находится в пределах $6.0 \%$. 


\section{Обсуждение результатов}

Химическая и энергетическая неоднородность поверхности частиц ППК обусловливает разный характер взаимодействия одних и тех же катионов с различными участками поверхности. В рамках физической адсорбции различают неспецифическую адсорбцию, связанную с образованием внешнесферных поверхностных комплексов, и более избирательную специфическую, когда происходит образование внутрисферных комплексов катионов переходных металлов либо их гидролизованных форм с поверхностными функциональными группами [5]. Установлено [6], что в почве существует обратимое динамическое равновесие между ионами металла, находящимися в почвенном растворе, обменно поглощенными ППК и специфически сорбированными неорганическими почвенными компонентами.

Для характеристики взаимодействия ионов никеля с ППК исследуемых региональных почв построены зависимости количества поглощенных ионов металла от его равновесной концентрации (рис. 1). Характер изотерм дерново-подзолистой, дерново-карбонатной и серой лесной почв указывает на высокую способность к поглощению ионов никеля из раствора. Прямолинейный участок кривой как неспецифической, так и специфической сорбции при концентрациях растворов никеля от 0.14 до 2.8 мМ располагается под бо́льшим углом наклона к оси абсцисс, свидетельствуя об интенсивной сорбции металла, что подтверждается величиной степени поглощения никеля ППК (табл. 2-4). По классификации Гильса [7] изотермы обоих типов адсорбции исследуемых почв можно отнести к L-классу тип 1, или L-max, соответствующие минимальным изменениям формы изотермы и заполнению монослоя Ленгмюра, и характеризуются высоким химическим сродством к поверхности адсорбента. Согласно классификации Спозито [5], форма изотерм обоих видов сорбции никеля у всех почвенных образцов в примененном диапазоне концентраций металла относится к группе IA, что также указывает на очень высокое сродство Ni к активным центрам ППК.

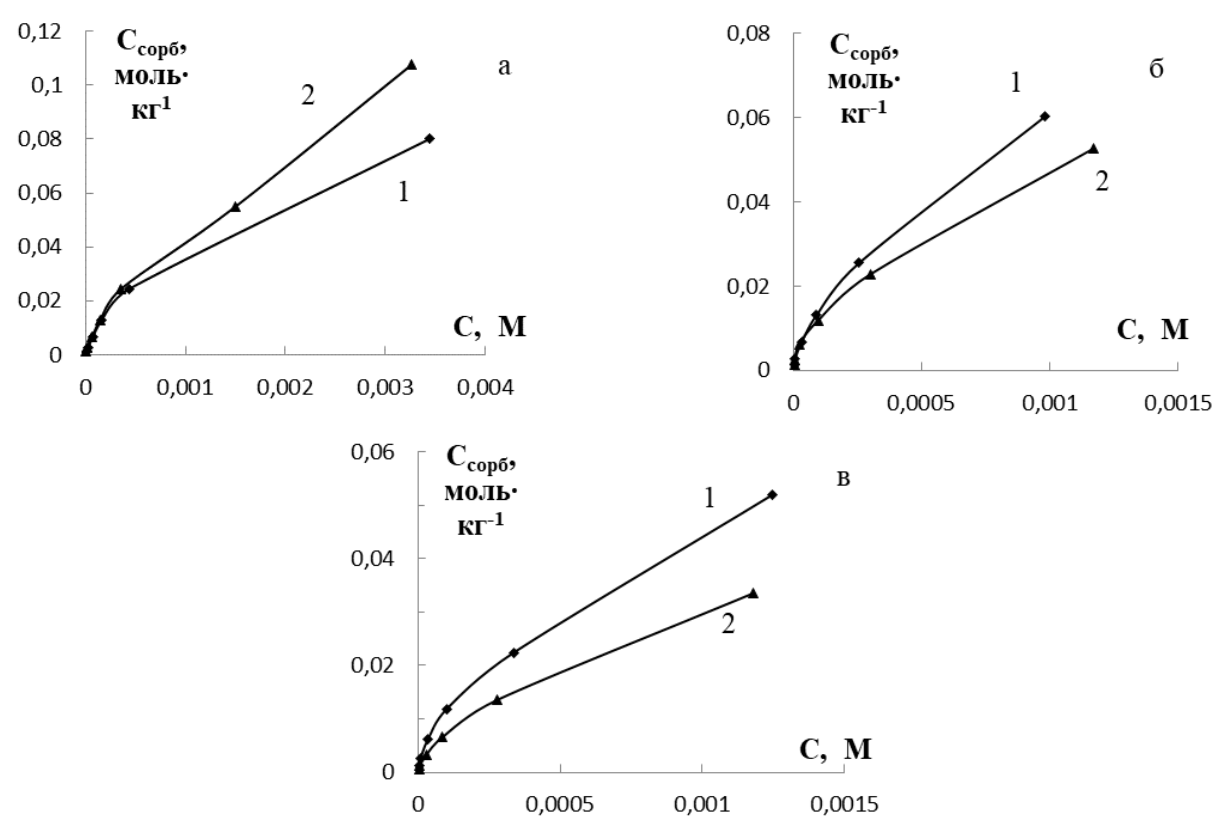

Рис. 1. Неспецифическая (1) и специфическая (2) сорбция ионов никеля дерново-подзолистой (а), дерново-карбонатной (б) и серой лесной (в) почвами

Fig. 1. Nonspecific (1) and specific (2) sorption of nickel ions by sod-strong podzolic (a), sod-carbonate (b) and grey forest podzolic (c) soils 
При внесении раствора с увеличенной концентрацией металла в 50 раз степень неспецифической сорбции (в процентах) дерново-подзолистой почвой уменьшалась практически вдвое (табл. 2), в то время как для специфической адсорбции данный показатель снижался в 1.2 раза. Присутствие в почвенном растворе ионов кальция высокой концентрации, адсорбирующихся ППК неспецифически, вероятно, значительно снижает число центров сорбции и приводит к существенному подавлению ионообменного поглощения ионов никеля, особенно с увеличением его концентрации (рис.1а, табл. 2). В случае специфической адсорбции с ионообменными центрами ППК, изначально насыщенными ионами кальция, идет избирательное поглощение почвой металла за счет образования координационных соединений, поэтому и характеристики сорбционного процесса с увеличением концентрации никеля уменьшаются не так интенсивно. Коэффициенты селективности $[8,9]$, а также степень поглощения специфической сорбции претерпевают меньшие изменения с ростом концентрации вводимого металла, подтверждая избирательность процесса специфической сорбции никеля.

Таблица 2. Адсорбция ионов никеля дерново-подзолистой почвой Table 2. Adsorption of nickel ions by sod-strong podzolic soil

\begin{tabular}{|c|c|c|c|c|c|c|c|}
\hline \multirow[b]{2}{*}{$\begin{array}{l}\text { № } \\
\Pi / \text { ח }\end{array}$} & \multirow[b]{2}{*}{$\mathrm{C}_{0}, \mathrm{M}$} & \multicolumn{3}{|c|}{ Неспецифическая } & \multicolumn{3}{|c|}{ Специфическая } \\
\hline & & $\begin{array}{c}\text { Степень } \\
\text { сорбции, } \\
\%\end{array}$ & $\mathrm{~m}_{\text {сорб}}, \Gamma$ & $K_{\text {селект }}$ & $\begin{array}{c}\text { Степень } \\
\text { сорбции, } \\
\%\end{array}$ & $\mathrm{~m}_{\text {сорб, } Г}$ & $K_{\text {селект }}$ \\
\hline 1 & 0.000140 & 92 & 0.00136 & 10.7 & 95 & 0.00141 & 17.7 \\
\hline 2 & 0.000280 & 92 & 0.00272 & 10.7 & 95 & 0.00281 & 17.7 \\
\hline 3 & 0.000700 & 90 & 0.00666 & 8.8 & 91 & 0.00676 & 10.2 \\
\hline 4 & 0.001401 & 89 & 0.01313 & 8.2 & 90 & 0.01330 & 9.1 \\
\hline 5 & 0.002802 & 84 & 0.02497 & 6.5 & 87 & 0.02584 & 8.0 \\
\hline 6 & 0.007004 & 51 & 0.03764 & 6.4 & 79 & 0.05813 & 6.7 \\
\hline
\end{tabular}

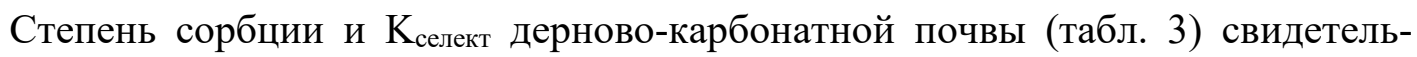
ствуют о большом сродстве никеля ко всем реакционным центрам ППК, при этом таких центров, способных поглощать металл, достаточно много, и при невысоких концентрациях никеля он интенсивно поглощается всеми их типами независимо от прочности образующихся связей, т.е. от типа сорбции. В интервале концентраций никеля 0.14-2.8 мМ зафиксировано небольшое преимущество ионообменной адсорбции (рис. 1б), что объясняется заполнением всех активных реакционноспособных центров ППК с наиболее прочными связями [10] по специфическому механизму уже при его малых концентрациях. Увеличение концентрации металла вовлекает в сорбцию все более слабые центры, вследствие чего начинает преобладать ионообменный механизм фиксирования никеля ППК.

Согласно коэффициентам селективности у серой лесной почвы (табл.4) преобладают ионообменные процессы в закреплении металла ППК по сравнению с образованием координационных связей, что может быть объяснено повышенным содержанием гумуса (табл. 1) с большим числом поверхностно-активных функциональных групп по сравнению с другими почвами. Превалирование неспецифического типа адсорбции подтверждается также изотермами (рис. 1в), поскольку при одной и той же равновесной концентрации никеля количество поглощенного почвой металла больше в случае ионного обмена. 
Таблица 3. Адсорбция ионов никеля дерново-карбонатной почвой Table 3. Adsorption of nickel ions by sod-carbonate soil

\begin{tabular}{|c|c|c|c|c|c|c|c|}
\hline \multirow[b]{2}{*}{$\begin{array}{c}\text { № } \\
\Pi / \Pi\end{array}$} & \multirow[b]{2}{*}{$\mathrm{C}_{0}, \mathrm{M}$} & \multicolumn{3}{|c|}{ Неспецифическая } & \multicolumn{3}{|c|}{ Специфическая } \\
\hline & & $\begin{array}{c}\text { Степень } \\
\text { сорбции, } \\
\%\end{array}$ & 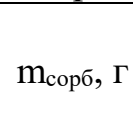 & $K_{\text {селект }}$ & $\begin{array}{c}\text { Степень } \\
\text { сорбции, } \\
\%\end{array}$ & 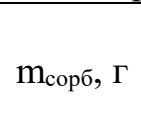 & $K_{\text {селект }}$ \\
\hline 1 & 0.000140 & 97 & 0.00144 & 28.8 & 97 & 0.00133 & 26.8 \\
\hline 2 & 0.000280 & 98 & 0.00290 & 21.0 & 98 & 0.00267 & 23.5 \\
\hline 3 & 0.000700 & 95 & 0.00706 & 16.2 & 97 & 0.00658 & 22.4 \\
\hline 4 & 0.001401 & 94 & 0.01385 & 11.9 & 92 & 0.01259 & 10.0 \\
\hline 5 & 0.002802 & 91 & 0.02691 & 9.1 & 88 & 0.02407 & 6.8 \\
\hline 6 & 0.007004 & 86 & 0.06364 & 8.2 & 82 & 0.05568 & 55 \\
\hline
\end{tabular}

Таблица 4. Адсорбция ионов никеля серой лесной почвой

Table 4. Adsorption of nickel ions by grey forest podzolic soil

\begin{tabular}{|c|c|c|c|c|c|c|c|}
\hline \multirow{2}{*}{ № п/п } & \multirow{2}{*}{$\mathrm{C}_{0}, \mathrm{M}$} & \multicolumn{3}{|c|}{ Неспецифическая } & \multicolumn{3}{c|}{ Степень } \\
\cline { 3 - 8 } & $\begin{array}{c}\text { сорбции, } \\
\%\end{array}$ & $\mathrm{~m}_{\text {сорб, Г }}$ & $K_{\text {селект }}$ & $\begin{array}{c}\text { Степень } \\
\text { сорбции, } \\
\%\end{array}$ & $\mathrm{~m}_{\text {сорб, } \Gamma}$ & $K_{\text {селект }}$ \\
\hline 1 & 0.000140 & 97 & 0.00132 & 21.8 & 97 & 0.00133 & 11.9 \\
\hline 2 & 0.000280 & 97 & 0.00264 & 18.7 & 97 & 0.00266 & 11.4 \\
\hline 3 & 0.000700 & 95 & 0.00645 & 11.2 & 96 & 0.00650 & 7.0 \\
\hline 4 & 0.001401 & 92 & 0.01255 & 7.7 & 93 & 0.01271 & 4.9 \\
\hline 5 & 0.002802 & 87 & 0.02368 & 4.7 & 89 & 0.02429 & 3.2 \\
\hline 6 & 0.007004 & 81 & 0.05490 & 3.7 & 82 & 0.05563 & 3.0 \\
\hline
\end{tabular}

Среди исследованных образцов почв только у дерново-подзолистой почвы зафиксировано преобладание специфического механизма сорбции никеля над ионообменным во всем интервале концентраций металла, вносимого с раствором (рис. 1, табл. 2), что обусловливает его более прочную фиксацию ППК. Данное явление можно объяснить с точки зрения химического состава почвы (табл. 1): дерновоподзолистая почва обладает минимальным количеством гумуса по сравнению с другими почвами, что уменьшает возможность сорбции по неспецифическому механизму, с другой стороны, у нее имеется достаточно большое количество полуторных оксидов, позволяющих активно поглощать ионы металла специфически. При одинаковой равновесной концентрации никеля в почвенном фильтрате (рис.1) наибольшее количество металла поглощается дерново-карбонатной почвой по ионообменному механизму, несколько меньше и примерно одинаковое количество никеля фиксируется дерново-подзолистой почвой специфически и серой лесной - неспецифически; что обусловлено соотношением органической и минеральной частей исследуемых почв.

Согласно [11], адсорбция никеля достигает максимума примерно при $\mathrm{pH} 6$, полученные нами данные (рис.2) согласуются с этим утверждением. Исходя из значения константы гидролиза никеля по первой ступени [12], в условиях эксперимента преобладающей формой металла в растворе является его катион $\mathrm{Ni}^{2+}$.

pH равновесных почвенных фильтратов скачкообразно уменьшается по сравнению с $\mathrm{pH}$ вводимого раствора никеля на 0.5 единицы у дерново-подзолистой почвы, на 0.2 единицы - у дерново-карбонатной и на 0.77 - у серой лесной почвы, что обусловлено как вытеснением катионами никеля протонов из ППК, так и прямым обменом между негидролизованной формой ионов $\mathrm{Ni}^{2+}$ и $\mathrm{Ca}^{2+}$ из почвы, при этом ио- 
ны кальция, переходящие в раствор, подвергаются гидролизу, также высвобождая ионы водорода[12].

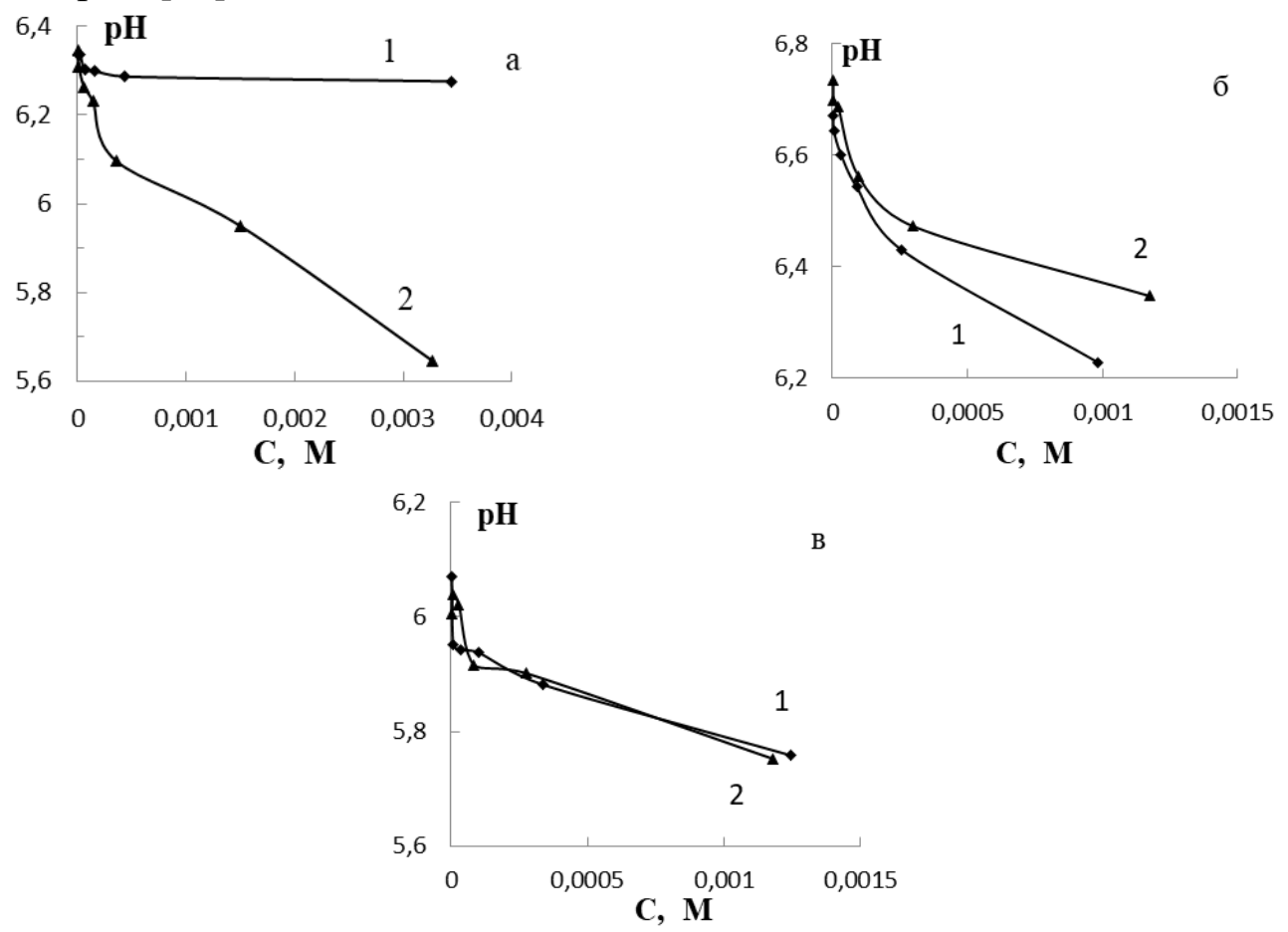

Рис. 2. $\mathrm{pH}$ равновесных растворов никеля неспецифической (1) и специфической

(2) сорбции дерново-подзолистой (a), дерново-карбонатной (б) и серой лесной (в) почвами

Fig. 2. $\mathrm{pH}$ of equilibrium solutions of nickel with nonspecific (1) and specific (2) sorption by sod-strong podzolic (a), sod-carbonate (b) and grey forest podzolic (c) soils

Во всем диапазоне вносимых концентраций металла величина $\mathrm{pH}$ фильтрата дерново-подзолистой почвы в варианте неспецифической адсорбции (рис. 2а) остается практически неизменной, что свидетельствует об отсутствии обменных реакций ионов никеля с протонами ППК. В варианте специфической адсорбции увеличение концентрации никеля вызывает уменьшение $\mathrm{pH}$ приблизительно на 0.4 единицы, свидетельствуя о высвобождении протонов, что указывает на достаточно интенсивное поглощение никеля почвой за счет образования внутрисферных поверхностных комплексов с активными сорбционными центрами ППК $[13,14]$ во всем исследуемом концентрационном диапазоне металла. У дерново-карбонатной почвы (рис.2б) зафиксировано монотонное уменьшение величины $\mathrm{pH}$ обоих типов сорбционного процесса во всем интервале концентраций никеля, при этом при одинаковой равновесной концентрации металла более кислой реакцией обладают почвенные фильтраты ионообменного типа, что указывает на более активное неспецифическое поглощение металла почвой и переход в почвенный раствор ионов водорода из твердой фазы. Величина $\mathrm{pH}$ фильтратов серой лесной почвы (рис. 2в) с ростом концентрации металла для обоих типов сорбции уменьшается практически одинаково, что обусловлено равной вероятностью протекания сорбционных процессов по обоим механизмам.

\section{Заключение}

В статических условиях изучены механизмы адсорбции ионов никеля на трех типах почв Удмуртии. Изотермы ионообменной и специфической сорбции по клас- 
сификации Гильса относятся к ленгмюровскому типу и указывают на высокое сродство ионов никеля к активным центрам ППК всех исследуемых почв. С увеличением концентрации металла преобладает ионообменный механизм его фиксирования почвами, при невысоких концентрациях никеля в соответствии со значениями степени сорбции и коэффициента селективности оба процесса равновероятны. За исключением ионообменной сорбции никеля дерново-подзолистой почвой, с увеличением концентрации металла происходит снижение величины рН почвенного раствора. Специфически адсорбированные катионы никеля за счет более прочной связи с ППК относительно малоподвижны по сравнению с катионами, сорбированными по ионообменному типу, что препятствует их переходу в жидкую фазу.

Изучение механизмов накопления ионов никеля в почвах позволяет предсказать возможность их миграции в системе твердая фаза - почвенный раствор, являющейся важной задачей, решение которой позволяет оценивать и прогнозировать состояние почвенного покрова, разрабатывать методы и проводить мероприятия по снижению поступления поллютантов в окружающую среду и ликвидации последствий в случае чрезвычайных ситуаций.

\title{
Список литературы
}

1. Аристархов А.Н., Харитонова А.Ф. // Плодородие. 2002. № 3. С.22-24.

2. Водяницкий Ю.Н., Ладонин Д.В., Савичев А.Т. Загрязнение почв тяжелыми металлами. М. Россельхозакадемия. 2012. 305 с.

3. Ковриго В.П. Почвы Удмуртской Республики. Ижевск. РИО ИжГСХА. 2004. 490 с.

4. Кречетов П.П., Дианова Т.М. Химия почв. Аналитические методы исследования. М. МГУ. 2009. 148 с.

5. Соколова Т.А., Трофимов С.Я. Сорбционные свойства почв. Адсорбция. Катионный обмен. Тула. Гриф и К. 2009. 172 с.

6. Ладонин Д.В., Пляскина О.В. // Почвоведение. 2004. № 5. С. 537-545.

7. Путилина В.С., Галицкая И.В., Юганова Т.И. Адсорбция тяжелых металлов почвами и горными породами. Характеристики сорбента, условия, параметры и механизмы адсорбции. Новосибирск. ГПНТБ СО РАН. 2009. 155 с.
8. Х Хаданович А.В. // Известия Гомельского государственного университета. 2016. Т. 96. № 3. C.70-74.

9. Никифорова Т.Е. Дисс. докт. хим. наук. Иваново. 2014. 365 с.

10. Moreira.C.S., Casagrande J.C., Alleoni L.R.F., D’Camargo O.A. et al // J.of Soilsand Sediments. 2008. Vol.8. pp. 442-451.

11. Mellis E.V., da Cruz MCP, Casagrande J.C. // Scientia Agricola. 2004. Vol. 61. No 2, pp. 190195.

12. Пинский Д.Л., Курочкина Г.Н. Почвенные процессы и пространственно-временная организация почв. М. 2006. Наука. 568 с.

13. Ramachandran V., D'Souza S.F. // J. of Soil Sci. and Plant Nutrition. 2013. Vol. 13. No 1. pp. 165-173

14. Plassard. F., Winiarski. T., Petit-Ramel M. // Journal of Contaminant Hydrology. 2000. Vol. 42. pp. 99-111.

\section{A study of the mechanisms of adsorption of nickel ions by different types of soils in Udmurtia}

\author{
(C) 2020 Shumilova M.A., Petrov V.G. \\ Udmurt Federal Research Center of the Ural Branch of the Russian Academy of Sciences, \\ Izhevsk, Russian Federation
}

The share of soils contaminated with nickel in Russia (2.8\%) among other heavy metals (HM) is very significant, which is due to the diversity of anthropogenic sources of the metal. In order to predict the migration of an element in the soil and development of technologies for land reclamation under emergency conditions, the study of the process of its absorption by the humus horizon of soils is required. The presented 
study is devoted to the investigation of the specific and nonspecific adsorption of nickel based on the example of typical soils of the Udmurt Republic.

The object of the study was the upper humus horizons of three types of soils of Udmurtia: sodstrong podzolic lightly washed soil, sod-carbonate lightly washed soil, and grey forest podzolic soils. In order to minimize the effect of ion exchange reactions on specific sorption, the soils were preliminarily saturated with calcium from an aqueous $0.01 \mathrm{M} \mathrm{CaCl}_{2}$ solution, after the samples were dried. The soil suspension was obtained by mixing air-dry soil samples with a solution with a variable nickel concentration in a ratio of 1:10, stirred on a rotator, and allowed to stand for two days. The equilibrium concentration of nickel ions in the soil filtrate was determined by atomic absorption spectrometry with electrothermal atomization.

According to the Giles classification, the isotherms of ion-exchange and specific sorption of nickel belong to the Langmuir type and indicate a high affinity of metal ions to the active centres of the soil absorbing complex (SAC) of all studied soils. With an increase in the metal concentration from 1.4 to $7.0 \mathrm{mM}$, the maximum decrease in the degree of nonspecific sorption was recorded for sod-strong podzolic soil by almost two fold, while for specific adsorption, the value decreased by 1.2 times. Among the studied soil samples, only in the sod-strong podzolic the predominance of the specific mechanism of nickel sorption over the ionexchange one was recorded in the entire range of concentrations of the introduced metal, which determines its more strong fixation by SAC.At a high concentration of the introduced metal (1.4-7.0 mM) for sodcarbonate and grey forest soils, a slight predominance of ion-exchange adsorption compared to the specific one was recorded.

It was found that, for almost all soils, with an increase in nickel concentration, the $\mathrm{pH}$ of the soil solution decreases. Only in the case of ion-exchange sorption of sod-strong podzolic soil was an unchanged $\mathrm{pH}$ recorded, which indicates the absence of exchange reactions of nickel ions with the protons of SAC.

Keywords: nickel, specific and non-specific adsorption, adsorption isotherm, soil

\section{References}

1. AristarkhovA.N., Kharitonova A.F., vosibirsk, GPNTB SB RAS Pub., 2009, 155 p.

Plodorodie, 2002, No 3, pp. 22-24.

8. Khadanovich A.V., Izvestiya gomel'skogo

2. Vodyanitskiy Yu.N., Ladonin D.V., Savichev

A.T., Zagryazneniye pochv tyazhelymi metallami, M., Russian Agricultural Academy Publ., 2012, $305 \mathrm{p}$.

3. Kovrigo V.P. Pochvy Udmurtskoy Respubliki, Izhevsk, IzhGSKHA Publ., 2004, 490 p.

4. Krechetov PP., Dianova T.M., Khimiya pochv. Analiticheskiye metody issledovaniya, M., MGU, 2009, 148 p.

5. Sokolova T.A., Trofimov S.Ya. gosudarstvennogo universiteta, 2016, Vol. 96, No 3, pp. 70-74.

9. Nikiforova T.Ye. Diss. dokt. khim. nauk. Ivanovo, 2014, $365 \mathrm{p}$.

10. Moreira. C.S., Casagrande. J.C., Alleoni. L.R.F., D'Camargo O.A. et al., J. of Soils and Sediments, 2008, Vol. 8, pp. 442-451.

11. Mellis E.V., da Cruz MCP, Casagrande J.C., Scientia Agricola, 2004, Vol. 61, No 2, pp. 190Sorbtsionnyye svoystva pochv. Adsorbtsiya. Kationnyy obmen, Tula, Grif and K. Publ., 2009, $172 \mathrm{p}$.

6. Ladonin D.V., Plyaskina O.V., Pochvovedenie, 2004, No 5, pp. 537-545.

195.

12.Pinskiy D.L., Kurochkina G.N. Pochvennyye protsessy i prostranstvenno-vremennaya organizatsiya pochv. M., SciencePubl., 2006, 568 p.

7. Putilina V.S., Galitskaya I.V., Yuganova T.I. Adsorbtsiya tyazhelykh metallov pochvami i gornymi porodami. Kharakteristiki sorbenta, usloviya, parametry i mekhanizmy adsorbtsii, No-

Шумилова Марина Анатольевна - старший научный сотрудник лаборатории информационноизмерительных систем, к.х.н., доцент, Удмуртский федеральный исследовательский центр УрО РАН, Ижевск

Петров Вадим Генрихович - ведущий научный сотрудник лаборатории информационноизмерительных систем, д.Х.н., Удмуртский федеральный исследовательский центр УрО РАН, Ижевск

13. Ramachandran V., D'Souza S.F., J. of Soil Sci. and Plant Nutrition, 2013, Vol. 13, No 1, pp. 165-173.

14.Plassard. F., Winiarski. T., Petit-Ramel M., Journal of Contaminant Hydrology, 2000, Vol. 42, pp. 99-111.

Shumilova Marina A. - senior researcher at the laboratory of information and measurement systems, Ph.D (chemistry), associate professor, Udmurt Federal Research Center of the Ural Brunch of the RAS, Izhevsk

Petrov Vadim G. - Leading Researcher at the laboratory of information and measurement systems, grand Ph.D (chemistry), Udmurt Federal Research Center of the Ural Brunch of the RAS, Izhevsk 